\title{
OCORRÊNCIA DE LEPIDÓPTEROS-PRAGA NA CULTURA DO ALGODOEIRO TRANSGÊNICO (BT) E CONVENCIONAL CULTIVADO NO SISTEMA ADENSADO E NÃO-ADENSADO COM E SEM APLICAÇÃO DE INSETICIDAS
}

\author{
Daniele Romano ${ }^{1}$, Geraldo Papa ${ }^{2}$
}

\begin{abstract}
1 Engo . Agroo. MSc. Consultor na área de produção vegetal na empresa Bettini Consultoria Agrícola, Primavera do Leste (MT).

2 Professor Assistente Doutor do Departamento de Fitossanidade, Engenharia Rural e Solos, da Faculdade de Engenharia / UNESP Campus de Ilha Solteira (SP)
\end{abstract}

RESUMO: A cultura do algodoeiro apresenta um complexo de pragas que podem proporcionar danos na produtividade e qualidade da fibra. O sistema adensado de cultivo se diferencia do sistema de semeadura não-adensado pelo maior número de plantas na mesma área, obtendo maior precocidade no ciclo, podendo ocorrer impacto na ocorrência e manejo de insetos. No Brasil o algodão com resistência a insetos lepidópteros Bollgard I (Bt) foi introduzido em 2005 e uma das variedades foi a NuOpal. O objetivo deste trabalho foi avaliar a ocorrência da falsa-medideira (Chrysodeixis includens), lagarta-curuquerê (Alabama argillacea) e lagarta-eridanea (Spodoptera eridanea) na cultura do algodoeiro transgênico com a variedade NuOpal e algodoeiro sem a tecnologia $\mathrm{Bt}$ com a variedade DeltaOpal, cultivado no sistema adensado e não-adensado, com e sem aplicação de inseticidas, em Primavera do Leste - MT, conduzido na $2^{\text {a }}$ Safra de 2010, no Campo Experimental do Instituto Mato Grossense do Algodão - IMAmt. O monitoramento das pragas foi realizado em 10 plantas ao acaso por parcela, contando-se as lagartas, separandoas por espécie. Pela análise dos resultados conclui-se que: os tratamentos com a cultivar NuOpal apresentam as menores incidências de lagartas de A. argillacea e $C$. includens em relação a cultivar DeltaOpal, o que não ocorre para a espécie $S$. eridanea. A cultivar $\mathrm{NuOpal}$, apresenta menor percentual de desfolha provocadas pelas lagartas. A cultivar DeltaOpal sofre mais desfolha no sistema de cultivo adensado que no cultivo não-adensado, enquanto que a cultivar NuOpal não difere no percentual de desfolha, independente do espaçamento adotado. $\mathrm{O}$ sistema de cultivo adensado produz significativamente mais algodão em caroço que o sistema não-adensado e os tratamentos com aplicação de inseticida mantem o potencial produtivo da cultura.

Palavras-chave: Gossypium hirsutum. Resistência a insetos. Densidade populacional.

\section{OCCURRENCE OF PESTS IN COTTON CROP TRANSGENIC (BT) AND NON-BT GROWING ON THE CONVENTIONAL SPACED AND NARROW ROW COTTON WITH AND WITHOUT PESTICIDES APPLICATION}

\begin{abstract}
The cotton crop presents a complex of pests that can provide damage to the productivity and fiber quality. The narrow row cotton cultivation is different of the
\end{abstract}

Cultura Agronômica, Ilha Solteira,v.24, n.4, p.281-292, 2015 
conventional space system, by having a larger number of plants in the same area and obtain greater precocity in the cotton cycle, but can also occur impact on the occurrence and management of the insects. In Brazil cotton with resistance to lepidopteran insects, Bollgard I (Bt) was introduced in 2005 and one of the varieties was the NuOpal.The objective of this study was to evaluate the occurrence of caterpillars as Chrysodixis includens; Alabama argillacea and Spodoptera eridaneain transgenic crop variety NuOpal and non-Bt varietiy DeltaOpal, growing in the conventional and narrow row cotton, with and without insecticide in Primavera do Leste - MT, conducted at the 2nd harvest crop year 2010, in the Mato Grosso Experimental Cotton Institute- IMAmt. Pest monitoring was conduct aleatory in ten plants per plot, counting arthropods and separating them by species. Based on the results it is concluded that: treatments with NuOpal have lower incidences of A. argillacea and $C$. includens that DeltaOpal cultivar which does not observed for the $S$. eridanea species. NuOpal cultivar has the lowest percentage of defoliation caused by the caterpillars. The cultivar DeltaOpal have more percentage defoliation in narrow row cotton cultivation as the conventional space system, while NuOpal cultivar does not differ in the percentage defoliation, regardless of the adopted spacing. The narrow row cotton cultivation produces significantly more than the conventional and space system and treatments with insecticide application keep the crop yield potential.

Key words: Gossypium hirsutum. Insects resistance. Population density.

\section{INTRODUÇÃO}

O algodão é produzido por mais de 60 países, nos cinco continentes, sendo que cinco países - China, Índia, Estados Unidos, Paquistão e Brasil - despontam como os principais produtores da fibra. Além disso, a cultura do algodoeiro no Brasil produziu 4,2 milhões de toneladas em uma área de 1,12 milhões de hectares na safra 2013/2014, predominantemente em dois estados: Mato Grosso e Bahia, de acordo com dados da Conab (2014).

Entretanto, conforme Santos (2007) para se manter competitivo no mercado mundial, o Brasil precisa produzir em quantidade e qualidade, mas o avanço das mais diversas pragas na cultura traz aos produtores grandes desafios, porque a planta do algodão atrai, alimenta e hospeda permanentemente um complexo significativo de pragas. Dentro da ordem Lepdoptera, estão inseridas diversas espécies de lagartas que causam grandes danos em folhas, caules e flores diminuindo o potencial produtivo pela perda de tecido vegetal ou ainda causar danos em maçãs e capulhos, impactando diretamente na produção final que é a fibra do algodão, seja pela perda de peso ou qualidade para a indústria (SANTOS, 2007).

A primeira cultivar de algodão transgênico (Bt) comercial (Bollgard-I) foi gerado em 1989 e liberado para comercialização nos EUA e na Austrália em 1996/97. No Brasil a liberação ocorreu em 2005. O Bollgard-I possui o gene crylAc, que lhe confere resistência à lagarta-das-maçãs - Heliothis virescens (FABRÍCIUS, 1781); lagarta rosada - Pectinophora gossypiella (SAUND, 1844) e lagarta curuquerê - Alabama argillacea (HÜBNER, 1818), espécies que atacam o algodoeiro no Brasil de acordo com Barroso e Hoffmann (2007).

Cultura Agronômica, Ilha Solteira,v.24, n.4, p.281-292, 2015 
Segundo Silva et al. (2009), na safra 2008/2009, a semeadura de algodão adensado também aumentou em todas as regiões algodoeiras e estas iniciativas partiram das associações estaduais de produtores, com o argumento de melhorar o sistema em termos de lucratividade/área/ano, por ter o adensado menor ciclo da cultura, menor custo de produção e a produção de outra cultura antecessora ao algodão, como a soja e o feijão na safra normal.

O algodão adensado se caracteriza por uma semeadura tardia, no fim de janeiro a fevereiro, no qual a densidade de plantas utilizada é entre 180.000 a 250.000 plantas por hectare e a precocidade é alcançada pelo fato de cada planta produzir somente 5 a 7 capulhos, com porte máximo de $70-80 \mathrm{~cm}$ de altura no momento da colheita (BELOT et al., 2009).

O objetivo deste trabalho foi avaliar os efeitos da ocorrência das lagartas $C$. includens; A. argillacea e $S$. eridanea no algodoeiro transgênico com a variedade NuOpal e convencional com a variedade DeltaOpal, cultivado no sistema adensado e não-adensado com e sem inseticida, na região de Primavera do Leste-MT. Porém, as duas outras espécies de lagartas, $H$. virescens e $P$. gossypiella, mesmo sendo alvos da tecnologia não apresentaram níveis de incidência significativa na safra em questão para serem avaliadas.

\section{MATERIAL E MÉTODOS}

O experimento foi conduzido na $2^{\text {a }}$. Safra do ano agrícola 2010 no município de Primavera do Leste - MT, no Campo Experimental do Instituto Mato Grossense do algodão - IMAmt, numa área situada aproximadamente a 54¹1'45.8"W - 15³1'55.62"S, com altitude de 619 metros.

O relevo é de planalto com leves variações e o solo predominante é Latossolo Vermelho-Amarelo (LVA), distrófico argiloso de acordo com a Embrapa (1999).

O clima da região é classificado segundo Köppene Geiger (1928) como do tipo Aw, definido como tropical de savana com estação seca de inverno. Apresenta uma temperatura média de $25^{\circ} \mathrm{C}$, umidade relativa do ar no período chuvoso média de $98 \%$ e no período da seca esse índice cai para 30\%. A precipitação pluviométrica é de 1.800 mm anuais.

Antes da implantação do experimento a área encontrava-se em pousio, mas com restos culturais de soja anteriormente cultivada em sistema convencional.

O delineamento experimental empregado foi o de blocos casualizados, em esquema fatorial $2 \times 2 \times 2$, num total de oito tratamentos, com quatro repetições, totalizando trinta parcelas. Os tratamentos formaram a combinação de dois níveis do fator cultivar (NuOpal e DeltaOpal) x dois níveis do fator espaçamento (adensado e não-adensado) x dois níveis do fator inseticida para controle de lepidópteros (com aplicação e sem aplicação) de inseticidas quando do aparecimento de lagartas e seus índices de infestação. Cada parcela constou de $12 \mathrm{~m}$ de comprimento por 7,2 $\mathrm{m}$ de largura.

$\mathrm{Na}$ primeira etapa foi realizada a semeadura da área na época denominada safrinha (fevereiro/2010) com material resistente a lagartas de primeira geração utilizando a 
variedade NuOpal e da mesma forma com a variedade DeltaOpal, tanto no cultivo nãoadensado como no adensado. No cultivo não-adensado foi adotado um espaçamento entre linhas de 0,90 m; estande de dez plantas/m originando uma população média aproximada de $111 \mathrm{mil}$ plantas/ha e no cultivo adensado adotado um espaçamento entre linhas de 0,45 m; estande de dez plantas/m originando uma população aproximada de 222 mil plantas/ha. Já, os tratos culturais normais de uma lavoura de algodão foram realizados em todos os tratamentos.

As avaliações para monitorar as lagartas se deram a cada sete dias, tomando-se dez plantas ao acaso por parcela e observando a planta inteira. Foram contadas as lagartas, separadas por espécie e obtido o percentual de infestação das mesmas para então efetuar a pulverização de acordo com níveis de controle já estabelecidos pelas recomendações de literatura(PAPA, 2006). Também foram feitas avaliações em porcentagem (\%) da desfolha conforme escala diagramática proposta por Azevedo(1998).

Os tratamentos cultivados com a variedade DeltaOpal e com aplicação de inseticida prevista ao longo da safra, foram pulverizados para o controle de insetos lepidópteros (lagartas) e não foram pulverizados nos tratamentos da mesma variedade que estavam programados para não receberem inseticidas ao longo da safra, a fim de se verificar a flutuação populacional da praga. $\mathrm{O}$ mesmo procedimento, foi realizado com a variedade NuOpal, assim, os tratamentos que estavam designados a receber aplicação de inseticida foram aplicados conforme a necessidade obedecendo aos níveis de controle descritos e adaptados de Papa (2006) para as espécies, A. argillacea, C. includens e S. eridanea - 40\% de plantas infestadas ou $10 \%$ de desfolha. Os inseticidas aplicados foram (metomil) 0,8 1/ha e (novalurom) 0,150 1/ha, conforme doses usuais de bula.

Foi realizada a medição da produção de algodão em caroço, obtida através da colheitamanual das duas linhas centrais de cada parcela, com cinco metros de comprimento, aos 160 dias após a emergência da cultura.

Os dados das contagens de pragas e da colheita foram submetidos à análise de variância pelo teste $\mathrm{F}$ e as médias comparadas pelo teste de Tukey (5\%) utilizando-se o programa estatístico SAS (Statistical Analysis System) (SAS, 1999), versão 9.1. As avaliações sem ocorrência de pragas não foram analisadas.

\section{RESULTADOS E DISCUSSÃO}

Em relação a curuquerê-do-algodoeiro - A. argillacea, comparando-se os dados dos tratamentos observa-se que ocorreram diferenças significativas isoladas entre os cultivares NuOpal e DeltaOpal apesar de não ocorrer interação entre os fatores analisados.

A cultivar NuOpal (Tabela 1) até os 54 DAE, por conter a tecnologia Bt e que possui ação sob essa espécie de lagarta, proporcionou bom controle com apenas 0,37 lagartas, quando comparado a sua cultivar isogênica DeltaOpal, sem a tecnologia Bt que apresentou número médio de 4,68 lagartas.

Cultura Agronômica, Ilha Solteira,v.24, n.4, p.281-292, 2015 
O mesmo pode ser observado entre os 55 até os 116 dias após a emergência, onde foram verificadas diferenças significativas em favor do uso da cultivar NuOpal, que apresentou infestação de 0,12 lagartas, frente à DeltaOpal com número médio de 2,56 lagartas.

Essa diferença significativa é explicada pela expressão da proteína existente na cultivar Nuopal, que controla esta lagarta após ingestão das partes vegetativas, o que não ocorre na cultivar DeltaOpal.

Tabela 1. Número médio de lagartas curuquerê - A. argillacea, até os 54 dias e dos 55 aos 116 dias após a emergência (DAE) do algodoeiro em diferentes sistemas de manejo. Primavera do Leste - MT, $2^{\text {a }}$ safra 2010.

\begin{tabular}{lcc}
\hline \multirow{2}{*}{ Cultivar } & \multicolumn{2}{c}{ Número médio de lagartas $^{\mathbf{1}}$} \\
\cline { 2 - 3 } & Até 54 (DAE) & 55 aos 116 (DAE) \\
\hline NuOpal & $0,37 \mathrm{a} \pm 0,63$ & $0,12 \mathrm{a} \pm 0,38$ \\
DeltaOpal & $4,68 \mathrm{~b} \pm 0,63$ & $2,56 \mathrm{~b} \pm 0,38$ \\
\hline $\mathrm{CV}(\%):$ & 99,85 & 112,69 \\
\hline${ }^{*}$ Médias não seguidas pela mesma letra diferem entre si pelo teste de F em nível de 5\% de probabilidade de \\
erro.
\end{tabular}

Tomquelski (2009), ao estudar a ocorrência de pragas e custo de produção em algodoeiro geneticamente modificado $(\mathrm{Bt})$ e convencional, observou que o número de indivíduos desta lagarta foi maior no tratamento com o uso da cultivar DeltaOpal sem aplicação de inseticida em relação a cultivar NuOpal sem aplicação de inseticidas no ano de 2007. No entanto, no ano de 2008, na repetição do experimento, as cultivares não apresentaram diferenças em condições iguais de manejo.

Em um estudo realizado por Lima e Torres (2011), visando verificar a preferência para alimentação de $A$. argillacea em algodão Bt sob estresse hídrico, verificaram que na fase de lagartas não houve diferenças em relação à alimentação entre Bt e não Bt.

Independente do espaçamento adotado ser adensado $(0,45 \mathrm{~m})$ ou não-adensado $(0,90$ $\mathrm{m})$, estes não apresentaram diferenças significativas. Uma hipótese para isso é o fato das contagens das lagartas terem sido feitas em um número determinado de plantas igualmente para os dois sistemas, mas como no adensado temos maior número de plantas na mesma área plantada, caso seja feita a avaliação com contagem de lagartas por área, existe a tendência de esses índices sofrerem alterações. Tais resultados corroboram com os dados obtidos no estudo realizado por Rodrigues et al. (2011), o qual o objetivo foi avaliar a dinâmica populacional dos insetos-praga do algodoeiro no sistema de plantio adensado e não-adensado, em que verificaram não haver diferença na dinâmica populacional de $A$. argillacea entre tais sistemas.

Comparando também todos os tratamentos isolando o efeito da aplicação, ou seja, com ou sem aplicação de inseticida, dentro de uma mesma cultivar ou mesmo espaçamento, não se observa diferenças até os 54 dias após a semeadura, porque até a presente data nenhuma aplicação havia sido realizada.

Cultura Agronômica, Ilha Solteira,v.24, n.4, p.281-292, 2015 
Em relação à lagarta falsa-medideira - C. includens, ocorreram diferenças significativas isoladas para as cultivares, até os 54 DAE e dos 55 até 116 DAE, onde considerando o efeito do cultivar NuOpal (Tabela 2), respectivamente. Apesar desta variedade não ser recomendado para o controle desta espécie de lagarta, ocorreu um efeito de supressão da praga através do uso da cultivar contendo essa proteína.

Tabela 2. Número médio de lagartas falsa-medideira - C. includens, até os 54 dias e dos 55 aos 116 dias após a emergência (DAE) do algodoeiro em diferentes sistemas de manejo. Primavera do Leste - MT, $2^{\text {a }}$ safra 2010.

\begin{tabular}{lcc}
\hline \multirow{2}{*}{ Cultivar } & \multicolumn{2}{c}{ Número médio de lagartas $^{\mathbf{1}}$} \\
\cline { 2 - 3 } & Até $54(\mathrm{DAE})$ & $55 \mathrm{aos} 116(\mathrm{DAE})$ \\
\hline NuOpal & $0,38 \mathrm{a} \pm 0,30$ & $1,13 \mathrm{a} \pm 0,39$ \\
DeltaOpal & $2,31 \mathrm{~b} \pm 0,30$ & $3,38 \mathrm{~b} \pm 0,39$ \\
\hline $\mathrm{CV}(\%):$ & 89,18 & 69,43 \\
\hline${ }^{*}$ Médias não seguidas pela mesma letra diferem entre si pelo teste de F em nível de 5\% de probabilidade de \\
erro.
\end{tabular}

Estes dados concordam com os obtidos por Stewart et al. (2001), que relata que as cultivares geneticamente modificadas de algodoeiro com apenas a produção da proteína Cry1Ac não são consideradas eficientes contra algumas espécies de lepidópteros, todavia podem atuar de forma supressiva proporcionando prolongamento da fase larval e menor peso das lagartas.

Funichello et al. (2011) visando verificar os parâmetros biológicos de C. includensna cultivar DeltaOpal e na cultivar NuOpal, detectaram que a NuOpal apresentou maior duração da fase larval nesse lepidóptero que na DeltaOpal. Todavia, não apresentou diferenças significativas nos parâmetros da viabilidade da fase larval e peso das lagartas aos 12 dias de idade em relação à DeltaOpal. Os autores concluíram ainda que não houve preferência para alimentação de $C$. includens em relação às cultivares de algodão estudadas e que a cultivar NuOpal não apresenta resistência à $C$. includens.

Em relação ao espaçamento adotado, adensado ou não-adensado, não houve qualquer diferença significativa entre os tratamentos em qualquer data avaliada, o que confirma os dados obtidos no estudo realizado por Rodrigues et al. (2011), em que verificaram não haver diferença na dinâmica populacional de lagartas desfolhadoras como a C. includens entre tais sistemas.

Ainda sobre a $C$. includens, em relação à intervenção química ou o não uso da mesma, não houve qualquer diferença significativa em qualquer das épocas avaliadas.

Nas avaliações da espécie S. eridanea, comparando os dados de infestação de lagartascom e sem aplicação, constatou-se diferença significativa devido à intervenção química dos 55 aos 116 dias da emergência (Tabela 3).

Analisando o efeito dos cultivares NuOpal e DeltaOpal, no controle da lagarta $S$. eridanea, constatou-se não haver diferença, sendo que isto pode ser explicado pela baixa infestação da praga ao longo do experimento. Estes dados, em parte, discordam dos 
resultados obtidos por Nascimento e Miranda (2009), que realizaram um comparativo do manejo de pragas em algodão transgênico e convencional. Nele detectaram que os níveis de infestação de $S$. eridanea nos cultivares transgênicos foram mais elevados que no cultivar convencional (Não-Bt), denotando-se uma preferência da espécie por cultivares Bt e através do qual alegaram que lagartas do gênero Spodoptera, não alvos da proteína Cry1Ac expressa pelos cultivares transgênicos estudados (NuOpal e DP 90B), não estão suscetíveis à proteína. Os dados apresentados referentes à lagarta não alvo da proteína Cry $1 \mathrm{Ac}(S$. eridanea) evidenciaram nas condições deste experimento a necessidade de intervenção química quando atingir os níveis de controle.

Tabela 3. Número médio de lagartas eridanea - S. eridanea, dos 55 aos 116 dias após a emergência (DAE) do algodoeiro em diferentes sistemas de manejo. Primavera do Leste MT, $2^{\mathrm{a}}$ safra 2010.

\begin{tabular}{lc}
\hline Inseticida & Número médio de lagartas ${ }^{\mathbf{1}}$ \\
\hline Com aplicação & $1,06 \mathrm{a} \pm 0,42$ \\
Sem aplicação & $2,37 \mathrm{~b} \pm 0,42$ \\
\hline $\mathrm{CV}(\%):$ & 98,27 \\
\hline${ }^{1}$ Médias não seguidas pela mesma letra diferem entre si pelo teste de $\mathrm{F}$ em nível de $5 \%$ de probabilidade de \\
erro.
\end{tabular}

Em relação ao espaçamento adotado, adensado ou não-adensado, não houve diferenças significativas, confirmando os dados obtidos no estudo realizado por Rodrigues et al. (2011), em que verificaram não haver diferença na dinâmica populacional da lagarta $S$. eridanea. Os resultados podem ser explicados devido o número de plantas avaliadas serem as mesmas, sem levar em consideração a quantidade de plantas por hectare, que no adensado a população é quase o dobro de plantas comparado ao não-adensado.

Comparando o percentual de desfolha, ocorreram diferenças significativas na interação cultivar x espaçamento (Tabela 4), ocasionado pelo complexo de lagartas nas avaliações realizadas até os 69 DAE.

Tabela 4. Porcentagem média de desfolha, em plantas atacadas pelas lagartas curuquerê - $A$. argillacea, falsa-medideira $-C$. includense lagarta eridanea $-S$. eridanea, até os 69 dias após a emergência (DAE) do algodoeiro em diferentes sistemas de manejo. Primavera do Leste MT, $2^{\mathrm{a}}$ safra 2010.

\begin{tabular}{lcc}
\hline \multirow{2}{*}{ Cultivar } & \multicolumn{2}{c}{$\%$ de desfolha $^{\mathbf{1}}$} \\
\cline { 2 - 3 } & Adensado & Não-adensado \\
\hline NuOpal & 1,75 a $\mathrm{A} \pm 0,77$ & 1,12 a $\mathrm{A} \pm 0,77$ \\
DeltaOpal & $10,38 \mathrm{~b} \mathrm{~B} \pm 0,77$ & $5,62 \mathrm{~b} \mathrm{~A} \pm 0,77$ \\
\hline
\end{tabular}

CV (\%): 46,11

\footnotetext{
1* Médias não seguidas pela mesma letra, minúsculas nas colunas e maiúsculas nas linhas diferem pelo teste de Tukey em nível de $5 \%$ de probabilidade de erro.
}

Analisando o efeito da interação entre as cultivares e os espaçamentos, observa-se que independente do espaçamento utilizado, a cultivar NuOpal sofreu menor desfolha pelo

Cultura Agronômica, Ilha Solteira,v.24, n.4, p.281-292, 2015 
ataque do complexo de lagartas, quando comparado ao cultivar DeltaOpal. Já com a cultivar DeltaOpal, o espaçamento adensado apresentou maior índice de desfolha pelas lagartas em relação ao espaçamento não-adensado, nas condições deste experimento. Uma hipótese que pode explicar isso é o fato das mariposas estarem mais protegidas no ambiente proporcionado pelo cultivo adensado, consequentemente maior oviposição, maior número de lagartas e menor exposição ao controle químico e inimigos naturais, aumentando seu tempo de vida e causando maior desfolha.

De acordo com Ballaminut et al. (2007), em avaliação de cultivares de algodão em relação ao ataque de curuquerê, verificaram que as variedades transgênicas NuOpal e DP 90 B apresentaram elevado controle com alta infestação desta lagarta, não apresentando desfolha, quando comparadas às cultivares convencionais DeltaOpal e Deltapine Acala 90.

Com referencias à intervenção química ou o não uso da mesma, não houve qualquer diferença significativa entre os tratamentos em qualquer uma das épocas avaliadas.

Tabela 5. Produção de algodão em caroço média por hectare (ha), por tratamento, realizada aos 160 dias após a emergência (DAE) do algodoeiro em diferentes sistemas de manejo. Primavera do Leste - MT, $2^{\text {a }}$ safra 2010.

\section{Espaçamento}

Adensado $^{1}$

Não-adensado ${ }^{2}$

\section{Produtividade por hectare ${ }^{3}$}

$$
1707,75 \text { a } \pm 90,91
$$

$1402,20 \mathrm{~b} \pm 90,91$

$\mathrm{CV}(\%): 23,39$

${ }^{1^{*}} 0,45 \mathrm{~m}$ entre-linhas; ${ }^{2 * *} 0,90 \mathrm{~m}$ entre-linhas; ${ }^{* * * *}$ Médias não seguidas pela mesma letra diferem entre si pelo teste de F em nível de 5\% de probabilidade de erro.

De acordo com os dados obtidos de produção de algodão em caroço (Tabela 5) mostram diferenças significativas na produtividade quanto ao espaçamento utilizado, ou seja, o sistema de semeadura adensado $(0,45 \mathrm{~m})$ entre-linhas produziu $300 \mathrm{~kg}$ de algodão em caroço.ha $^{-1}$ a mais do que o sistema de semeadura convencional $(0,90 \mathrm{~m})$.

Tabela 6. Produção de algodão em caroço média por hectare (ha), por tratamento, aos 160 dias após a emergência (DAE) do algodoeiro em diferentes sistemas de manejo. Primavera do Leste - MT, $2^{\text {a }}$ safra 2010.

Inseticida $\quad$ Produtividade por hectare $^{3}$

Com aplicação ${ }^{1}$

Sem aplicação ${ }^{2}$
1752,02 a $\pm 90,91$

1357,92 b+90,91

CV (\%): 23,39

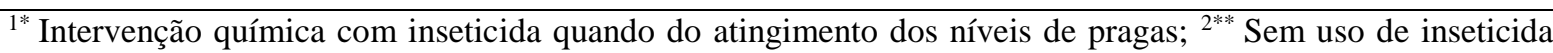
quando do atingimento dos níveis de pragas; ${ }^{3 * * *}$ Médias não seguidas pela mesma letra diferem entre si pelo teste de $\mathrm{F}$ em nível de $5 \%$ de probabilidade de erro.
}

A mesma manutenção da produção foi observada em relação à intervenção química durante a condução do experimento (Tabela 6), a qual quando utilizada produziu quase 400 
$\mathrm{kg}$ de algodão em caroço.ha ${ }^{-1}$ a mais em relação a não utilização de inseticidas para o controle das pragas ao longo do ciclo da cultura, demonstrando que quando se atingiu o nível de dano econômico, o uso da intervenção química foi realmente necessária para baixar a população das pragas.

Verificando as duas cultivares de algodão utilizadas NuOpal e DeltaOpal, não houve diferença em função do uso ou não da tecnologia Bt, no tocante a produção.

Tomquelski (2009), ao estudar a ocorrência de pragas e custo de produção em algodoeiro geneticamente modificado e convencional, observou que não ocorreram diferenças significativas entre as cultivares, na produtividade do algodoeiro, diferentemente deste experimento.

\section{CONCLUSÃO}

Os tratamentos com a cultivar transgênica NuOpal apresentam as menores incidências de lagartas de $A$. argillacea e $C$. includens, enquanto a espécie $S$. eridanea, não houve diferenças entre as cultivares.

A cultivar NuOpal obtém a menor desfolha pelo ataque do complexo de lagartas, quando comparado ao cultivar DeltaOpal, sendo que esta sofre mais desfolha no sistema de cultivo adensado do que no cultivo não-adensado. Já a cultivar NuOpal, independente do espaçamento adotado, não difere no percentual de desfolha.

O sistema de cultivo adensado produz significativamente mais algodão em caroço do que o sistema não-adensado.

Os tratamentos com aplicação de inseticida mantém o potencial produtivo da cultura, diferindo do manejo sem inseticida.

\section{AGRADECIMENTOS}

Ao professor Dr. Geraldo Papa, pelo incentivo demonstrado como orientador deste trabalho e pelas vezes que procurou corrigir meus defeitos visando melhorias profissionais.

Ao IMAmt pela oportunidade, ao Sr. Álvaro Sales e Sra. Juliana Sanches que propuseram este desafio; pelo apoio financeiro; aos pesquisadores e demais colaboradores.

À Faculdade de Engenharia de Ilha Solteira - SP (Universidade Estadual Paulista), e aos professores do Programa de Pós-Graduação em Agronomia (PPGA) da FEIS/UNESP.

\section{REFERÊNCIAS BIBLIOGRÁFICAS}

AZEVEDO, L. A. S.Manual de quantificação de doenças de plantas. Jaboticabal: Unesp, 1998.114p. 
ASSOCIAÇÃO BRASILEIRA DOS PRODUTORES DE ALGODÃO. Estatísticas: o algodão nomundo. Brasília: ABRAPA, 2012. Disponível em: http://www.abrapa.com.br/estatisticas/Paginas/Algodao-no-Mundo.aspx. Acesso em: 15 jan. 2012.

BALLAMINUT, C. E.; CHIAVEGATO, E. J.; MOREIRA, M. S.; GOTTARDO, L. C.; BRANDÃO, G. Cultivares transgênicas (Bollgard I) e não transgênicas em relação ao ataque de lagarta desfolhadora. In: CONGRESSO BRASILEIRO DO ALGODÃO, 6., 2007, Salvador. Anais... Campina Grande: Embrapa Algodão, 2007. 1 CD-ROM.

BARROSO, P. A. V.; HOFFMANN, L. V. Algodoeiros geneticamente modificados. In: FREIRE, E. C. (Ed.). Algodão no cerrado do Brasil. Brasília: ABRAPA, 2007. Cap. 4, p. 141-173.

BELOT, J. L.; DEGRANDE, P. E.; ANDRADE JUNIOR, E. R; FERRARI, S. Informativo Técnico IMAmt - Alerta para o Cultivo Adensado do Algodoeiro no Mato Grosso (Safra 2009). Primavera do Leste, 2009. não pag.

COMPANHIA NACIONAL DE ABASTECIMENTO - CONAB. Acompanhamento da safra brasileira de grãos, v.1 - Safra 2013/14, n.12 - Décimo Segundo Levantamento, Brasília: CONAB, p. 1-127, set. 2014. Disponível em: http://www.conab.gov.br/OlalaCMS/uploads/arquivos/14_09_10_14_35_09_boletim_graos _setembro_2014.pdf. Acesso em: 06 jul. 2015.

EMPRESA BRASILEIRA DE PESQUISA AGROPECUÁRIA- EMBRAPA - Centro Nacional de Pesquisa de Solos. Sistema brasileiro de classificação de solos. Brasília: Embrapa Produção da Informação, 1999. 412 p.

FUNICHELLO, M.; SOUZA, B. H. S.; GRIGOLLI, J. F. J.; RIBEIRO, A. A.; BUSOLI, A. C.; BOIÇA JÚNIOR, A. L. Evolução da cadeia para construção de um setor forte. In: CONGRESSO BRASILEIRO DE ALGODÃO, 8.; COTTON EXPO, 1., 2011, São Paulo. Anais... Campina Grande: Embrapa Algodão, 2011. p. 221-227. 1 CD-ROM.

KÖPPEN, W.; GEIGER, R. Klimate der Erde. Gotha: Verlag Justus Perthes, 1928.não pag.

LIMA, M. S.; TORRES, J. B. Produção da toxina Cry1Ac e preferência para alimentação e oviposição de Alabama argillacea em algodão $\mathrm{Bt}$ sob estresse hídrico. Pesquisa Agropecuária Brasileira, Brasilia, v. 46, n. 5, p.451-457, 2011.

NASCIMENTO, V. L.; MIRANDA, J. E. Sustentabilidade da cotonicultura brasileira e expansão dos mercados. In: CONGRESSO BRASILEIRO DO ALGODÃO, 7, 2009, Foz do Iguaçu. Anais... Campina grande: Embrapa Algodão, 2009. p. 648-653.

Cultura Agronômica, Ilha Solteira,v.24, n.4, p.281-292, 2015 
PAPA, G. Pragas e seu controle. In: MORESCO, E. (Org.). Algodão: pesquisas e resultados para o campo. Cuiabá: FACUAL, 2006. p. 206-239.

RODRIGUES, S. M. M.; SILVIE, P. J.; MENEZES, V. L.;VENERO, E. P.Evolução da cadeia para construção de um setor forte. In: CONGRESSO BRASILEIRO DE ALGODÃO, 8.; COTTON EXPO, 1., 2011, São Paulo. Anais... Campina Grande: Embrapa Algodão, 2011. p. 191-195. 1 CD-ROM.

SANTOS, W. J. Manejo das pragas do algodão com destaque para o cerrado brasileiro. In: FREIRE, E. C. (Ed.) Algodão no cerrado do Brasil. Brasília: ABRAPA, 2007. Cap. 12, p. 403-478.

SAS. SAS Software. Version 9.1. Cary, North Carolina: SAS Institute Inc., 1999.CD-ROM. SILVA, C. A. D.; BELTRAO, N. E. M.; FERREIRA, A. C. B.; SIlVA, O. R. R. F.; SUASSUNA, N. D. Algodoeiro herbáceo em sistema de cultivo adensado: atualidades e perspectivas. Campina Grande: Embrapa Algodão, 2009. 27 p. (Documentos, 219).

STEWART, S. D.; ADAMCZYCK, J. J.; KNIGHTEN, K. S.; DAVIS, F. M. Impact of Bt cotton expressing one or two insecticidal proteins of Bacillus thuringiensis Berliner on growth andsurvival of noctuid (Lepidoptera) larvae. Journal of Economic Entomology, Lanham, v. 94, n. 3, p.752-760, 2001.

TOMQUELSKI, G. V. Ocorrência de pragas e custo de produção em algodoeiro geneticamente modificado (Bt) e convencional. 2009. 108 f. Dissertação. (Doutorado em Agronomia - Sistemas de Produção Agrícola) - Faculdade de Engenharia, Universidade Estadual Paulista, Ilha Solteira, 2009. 
